\title{
Extraction Ability of 4-Benzoyl-3-phenyl-5-isoxazolone towards 4f-Ions into Ionic and Molecular Media
}

\author{
Maria Atanassova, $* * * \dagger$ Hiroyuki OKamura,* Ayano EguchI, $* * * *$ Yuki Ueda,* Tsuyoshi Sugita,* \\ and Kojiro SHIMOJo*i \\ *Advanced Science Research Center, Japan Atomic Energy Agency, Tokai, Ibaraki 319-1195, Japan \\ **Department of General and Inorganic Chemistry, University of Chemical Technology and Metallurgy, \\ 8 Kliment Okhridski blvd., 1756 Sofia, Bulgaria \\ ***Department of Chemistry, Faculty of Science, Toho University, 2-2-1 Miyama, Funabashi 274-8510, Japan
}

\begin{abstract}
The distribution constants of 4-benzoyl-3-phenyl-5-isoxazolone (HPBI) and deprotonated one ( $\left.\mathrm{PBI}^{-}\right)$between hydrophobic ionic liquid 1-butyl-3-methylimidazolium bis(trifluoromethanesulfonyl)imide $\left(\left[\mathrm{C}_{1} \mathrm{C}_{4} \mathrm{im}\right]\left[\mathrm{Tf}_{2} \mathrm{~N}\right]\right)$ and aqueous phases were determined, together with the acid-dissociation constant of HPBI. The solvent extraction of three selected lanthanoid ions $\left(\mathrm{La}^{3+}, \mathrm{Eu}^{3+}\right.$, and $\left.\mathrm{Lu}^{3+}\right)$ with HPBI from aqueous nitrate phase into $\left[\mathrm{C}_{1} \mathrm{C}_{4} \mathrm{im}\right]\left[\mathrm{Tf}_{2} \mathrm{~N}\right]$ has been investigated. Application of the ionic liquid as the extracting phase greatly enhanced the extraction performance of HPBI for lanthanoid ions compared with that in the chloroform system. A slope analysis was conducted in order to compare the results of the solution 4f-ion coordination chemistry in ionic and molecular media. The composition of the extracted species was established to be anionic tetrakis entities, $\mathrm{Ln}(\mathrm{PBI})_{4}^{-}$, for light, middle, and heavy lanthanoid ions in an ionic environment (Ln denotes lanthanoid ion). Nevertheless, the typical neutral chelate lanthanoid complexes of the type $\operatorname{Ln}(\mathrm{PBI})_{3}$ have been detected when the conventional molecular diluent chloroform was applied as an organic phase.
\end{abstract}

Keywords Lanthanoids, 4-benzoyl-3-phenyl-5-isoxazolone, ionic liquid, extraction

(Received April 11, 2018; Accepted May 10, 2018; Advance Publication Released Online by J-STAGE May 18, 2018)

\section{Introduction}

Nowadays, rare-earth elements are being evaluated as critical materials due to their vital role in advanced materials and cutting-edge technologies. The intragroup separation of lanthanoids (Lns) is an extremely difficult task because of their similar chemical properties. Additionally, there is some concern about a shortage of these metals with no viable substituents demonstrating identical performance worldwide.

In the last two decades, ionic liquids (ILs) have emerged as unique and versatile compounds possessing a number of advantageous tunable properties; as a consequence they have succeeded to gain tremendous attention from the separationscience community. ${ }^{1-4}$ As a matter of fact, the extraction of metal ions including Lns can be drastically enhanced by applying ILs to organic phases as alternatives to traditional systems, implicating classical molecular diluents, when enormous varieties of ligands have been studied in this regard during recent years. Nevertheless, that aforesaid ionic character really gives rise to a high extraction ability, which permits ionexchange mechanism incorporating an IL cation or anion. Unlike conventional molecular systems, where metals generally form neutral hydrophobic complexes, in IL systems the situation is remarkably different in view of intensive ion exchange that sometimes creates atypical complexes via multiple mechanism

$\dagger$ To whom correspondence should be addressed.

E-mail: shimojo.kojiro@jaea.go.jp (K. S.); ma@uctm.edu (M. A.) processes..$^{5-9}$ A variety of ligands developed to operate in molecular media have nowadays proven to be effective in ILs too, such as crown ethers, ${ }^{7,10,11} N, N, N^{\prime}, N^{\prime}$-tetraoctyldiglycolamide (TODGA), ${ }^{12} \quad$ octyl(phenyl)- $N, N$-diisobutylcarbamoylmethylphosphine oxide (CMPO), ${ }^{5,13,14} \beta$-diketones, ${ }^{6,7,9,15-18}$ calix[n]arenes $^{19-22}$ and other compounds. This has a supplemental advantage, so that researchers may draw on the massive library of known compounds, many of which are highly specific for a given group of metallic species, in order to design new ones.

The solvent extraction of Lns by the 4-benzoyl-3-phenyl-5isoxazolone (HPBI, Fig. 1) molecule has been extensively studied by Atanassova and co-researchers in a range of conventional molecular diluents $\left(\mathrm{CHCl}_{3}, \mathrm{C}_{6} \mathrm{H}_{6}, \mathrm{CCl}_{4}\right.$,<smiles>O=C(c1ccccc1)c1c(-c2ccccc2)noc1O</smiles>

HPBI<smiles>CCCCn1cc[n+](C)c1</smiles>

$$
\left[\mathrm{C}_{1} \mathrm{C}_{4} \mathrm{im}\right]\left[\mathrm{Tf}_{2} \mathrm{~N}\right]
$$

Fig. 1 Chemical structures of the chelating extractant and ionic liquid employed in this study. 
1,2-dichloroethane), including combinations with a wide variety of ligands, like crown ethers, ${ }^{23}$ p-tert-butylcalix[4]arenes, ${ }^{24,25}$ alkylammonium salts ${ }^{26}$ including Aliquat 336 in its perchlorate form too. ${ }^{27}$ Strong acidity due to the electron delocalization induced by the isoxazolone moiety makes 4 -acyl-5-isoxazolones an interesting class of analogs to $\beta$-diketones with potential application at strong acidic media for developing a separation process for both lanthanoids and actinoids. ${ }^{28-32}$ However, the complexation performance of this powerful chelating agent towards metallic species has not been evaluated in IL surroundings.

In the present study, the employment of a stronger chelating agent, HPBI, for the solvent extraction of $4 \mathrm{f}$-ions into an IL was studied. The ionic liquid, 1-butyl-3-methylimidazolium bis(trifluoromethanesulfonyl)imide, hereafter referred to as $\left[\mathrm{C}_{1} \mathrm{C}_{4} \mathrm{im}\right]\left[\mathrm{Tf}_{2} \mathrm{~N}\right]$ (Fig. 1), was used as the extracting medium because it is a water-immiscible hydrophobic IL with low viscosity. In an attempt to investigate the influence of the organic chemical ambiance i.e. ionic vs. molecular nature on the extraction process, the extraction test was performed in chloroform by applying the identical protocol. An effort was made to explore/understand the equilibrium mechanism with the main goal being to elucidate the nature of the complexes formed in the organic phase in order to propose a definitive explanation for metal-ion transfer into ILs.

\section{Experimental}

\section{Reagents and chemicals}

The commercial product HPBI (purity $>99 \%$, Fluka) was used as received. $\mathrm{La}\left(\mathrm{NO}_{3}\right)_{3} \cdot 6 \mathrm{H}_{2} \mathrm{O}, \mathrm{Eu}\left(\mathrm{NO}_{3}\right)_{3} \cdot 6 \mathrm{H}_{2} \mathrm{O}$, and $\mathrm{Lu}\left(\mathrm{NO}_{3}\right)_{3} \cdot 3 \mathrm{H}_{2} \mathrm{O}$ were purchased from Kishida Chemical Co., Ltd. (Osaka, Japan). The ionic liquid, $\left[\mathrm{C}_{1} \mathrm{C}_{4} \mathrm{im}\right]\left[\mathrm{Tf}_{2} \mathrm{~N}\right]$, was synthesized and purified with $82.9 \%$ yield, as described previously, ${ }^{33}$ and the quality was checked by ${ }^{1} \mathrm{H}$ NMR in acetone- $d_{6}$. The applied molecular diluent was chloroform (HPLC grade, 99.7\% Wako). Metal stock solutions containing each $\mathrm{Ln}(\mathrm{III})$ ion at a concentration of $10 \mathrm{mM}(1 \mathrm{M}=1 \mathrm{~mol}$ $\mathrm{dm}^{-3}$ ) were prepared by dissolving their nitrate salts in nitric acid, pH 2. High-purity deionized water $(18.2 \mathrm{M} \Omega \cdot \mathrm{cm})$ was used throughout this study. All other commercially available analytical-grade reagents were used without any further purification.

\section{Distribution of HPBI}

The aqueous phases were prepared by the addition of either $0.1 \mathrm{M} \mathrm{HCl}$ or $0.1 \mathrm{M} \mathrm{NaOH}$ to a $0.1 \mathrm{M} 2$-morpholinoethanesulfonic acid (MES) buffer. The $\left[\mathrm{C}_{1} \mathrm{C}_{4} \mathrm{im}\right]\left[\mathrm{Tf}_{2} \mathrm{~N}\right]$ phases were prepared by dissolving HPBI to give a concentration of $10 \mathrm{mM}$. Equal volumes $\left(0.7 \mathrm{~cm}^{3}\right)$ of the aqueous and IL solutions were mixed and shaken mechanically at $25^{\circ} \mathrm{C}$ for $30 \mathrm{~min}$ to attain distribution equilibrium. After phase separation by centrifugation, the $\mathrm{pH}$ in the aqueous phase at equilibrium was measured by a $\mathrm{pH}$ meter (Horiba F-72) with an accuracy $0.01 \mathrm{pH}$ unit. The equilibrated aqueous phases were diluted with $1 \mathrm{M} \mathrm{NaOH}$, and then the absorbance at $310 \mathrm{~nm}$ corresponding to the maximum absorption wavelength for $\mathrm{PBI}^{-}$was measured by using a UV/ Vis spectrophotometer (JASCO V-550) to determine the ligand concentration in the aqueous phase. The ligand concentration in the $\left[\mathrm{C}_{1} \mathrm{C}_{4} \mathrm{im}\right]\left[\mathrm{Tf}_{2} \mathrm{~N}\right]$ phase was determined in the same manner after dilution with $1 \mathrm{M} \mathrm{NaOH}$ in methanol- $\mathrm{H}_{2} \mathrm{O}(1: 1)$. The values of the molar absorptivity of $\mathrm{PBI}^{-}$in a $1 \mathrm{M} \mathrm{NaOH}$ aqueous solution and in a $1 \mathrm{M} \mathrm{NaOH}$ methanol- $\mathrm{H}_{2} \mathrm{O}(1: 1)$ solution were $9.0 \times 10^{3}$ and $9.2 \times 10^{3} \mathrm{dm}^{3} \mathrm{~mol}^{-1} \mathrm{~cm}^{-1}$, respectively. The recovery of the ligand for each sample was checked to confirm that the determination method of the ligand was appropriate. The distribution of the MES buffer components into the IL phase and the effect of the MES buffer on the distribution of ligand were regarded as being negligible. The distribution ratio of HPBI $\left(D_{\text {HPBI }}\right)$ was calculated as:

$$
D_{\mathrm{HPBI}}=\frac{[\mathrm{HPBI}]_{\mathrm{IL}}+\left[\mathrm{PBI}^{-}\right]_{\mathrm{IL}}}{[\mathrm{HPBI}]_{\mathrm{aq}}+\left[\mathrm{PBI}^{-}\right]_{\mathrm{aq}}}
$$

where the subscripts IL and aq denote the IL phase and the aqueous phase, respectively.

\section{Liquid-liquid extraction of lanthanoids}

The $\mathrm{pH}$ of the aqueous solutions was adjusted by the addition of either $\mathrm{HNO}_{3}$ or $\mathrm{NaOH}$ to a $0.1 \mathrm{M}$ MES buffer. To prepare each aqueous phase, a stock solution containing each Ln ion was added to the aqueous solutions to give $\mathrm{Ln}$ ion concentrations of $0.01 \mathrm{mM}$. Extracting phases containing HPBI in $\left[\mathrm{C}_{1} \mathrm{C}_{4} \mathrm{im}\right]\left[\mathrm{Tf}_{2} \mathrm{~N}\right]$ were prepared at concentrations of $1 \mathrm{mM}$ for the $\mathrm{pH}$ dependency test or 0.2 to $5 \mathrm{mM}$ for the HPBI concentration dependency test. For a comparison with the performance of IL, a conventional organic diluent, chloroform, containing HPBI was also prepared by the same procedure. Equal volumes $\left(0.5 \mathrm{~cm}^{3}\right)$ of the aqueous and extracting solutions were mixed and shaken mechanically at $25^{\circ} \mathrm{C}$ for $60 \mathrm{~min}(1800 \mathrm{rpm})$ to attain equilibrium. After separation of the two layers by $3 \mathrm{~min}$ centrifugation $(5000 \mathrm{rpm})$, the concentration of $\operatorname{Ln}(\mathrm{III})$ in the aqueous phase was determined by using an inductively coupled plasma mass spectrometer (ICP-MS, PerkinElmer NexION 300X). The metal concentration in the extracting phase was determined in the same manner after back-extraction with $1 \mathrm{M} \mathrm{HNO}_{3}$. The recovery of $\mathrm{Ln}$ (III) ions for each sample was checked to confirm no loss of metals into the interface and/or tube surface. The acidity of the aqueous phase at equilibrium was measured by a $\mathrm{pH}$ meter. The distribution ratio of $\operatorname{Ln}(\mathrm{III})(D)$ was calculated as

$$
D=\frac{\left[\operatorname{Ln}^{3+}\right]_{\text {aq,back }}}{\left[\operatorname{Ln}^{3+}\right]_{\text {aq, }, \mathrm{f}}}
$$

where $\left[\mathrm{Ln}^{3+}\right]_{\mathrm{aq}, \mathrm{f}}$ is the concentration of $\mathrm{Ln}^{3+}$ ion in the aqueous phase after extraction and $\left[\mathrm{Ln}^{3+}\right]_{\text {aq,back }}$ is its concentration after back-extraction. The extractability $(E)$ was evaluated as

$$
E=\frac{\left[\mathrm{Ln}^{3+}\right]_{\mathrm{aq}, \mathrm{back}}}{\left[\mathrm{Ln}^{3+}\right]_{\mathrm{aq}, \mathrm{f}}+\left[\mathrm{Ln}^{3+}\right]_{\mathrm{aq}, \mathrm{back}}} \times 100 .
$$

\section{Results and Discussion}

\section{Distribution equilibria of HPBI}

The distribution behavior of HPBI between the $\left[\mathrm{C}_{1} \mathrm{C}_{4} \mathrm{im}\right]\left[\mathrm{Tf}_{2} \mathrm{~N}\right]$ phase and the aqueous phase was investigated as a function of the $\mathrm{pH}$ in the aqueous phase. Figure 2 shows the relationship between $\log D_{\mathrm{HPBI}}$ and the aqueous phase $\mathrm{pH}$ in the $\left[\mathrm{C}_{1} \mathrm{C}_{4} \mathrm{im}\right]\left[\mathrm{Tf}_{2} \mathrm{~N}\right]$ system. In the lower $\mathrm{pH}$ region, the $\log D_{\mathrm{HPBI}}$ value approaches a constant value with decreasing $\mathrm{pH}$ in the aqueous phase. Furthermore, the $\log D_{\mathrm{HPBI}}$ value can be assumed to become constant in the higher $\mathrm{pH}$ region, as reported previously. ${ }^{34}$ It was, therefore, indicated that the neutral HPBI and the deprotonated anionic $\mathrm{PBI}^{-}$distribute into the IL phase. The distribution equilibrium of neutral HPBI is represented as follows:

$$
\mathrm{HPBI}_{\mathrm{aq}} \rightleftharpoons \mathrm{HPBI}_{\mathrm{IL}} \text {, }
$$




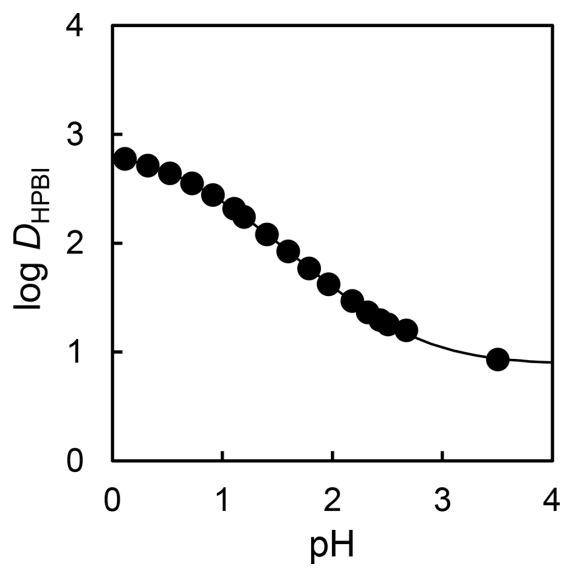

Fig. 2 Logarithmic distribution ratio of HPBI $\left(\log D_{\mathrm{HPBI}}\right)$ as a function of the equilibrium $\mathrm{pH}$ value of the aqueous phase in the $\left[\mathrm{C}_{1} \mathrm{C}_{4} \mathrm{im}\right]\left[\mathrm{Tf}_{2} \mathrm{~N}\right]$ system. The initial concentration of HPBI was $10 \mathrm{mM}$. The solid line was obtained by a non-linear least-squares fitting.

and the distribution constant of HPBI $\left(K_{\mathrm{D}, \mathrm{HPBI}}\right)$ is defined as

$$
K_{\mathrm{D}, \mathrm{HPBI}}=\frac{[\mathrm{HPBI}]_{\mathrm{IL}}}{[\mathrm{HPBI}]_{\mathrm{aq}}} .
$$

In contrast, the distribution equilibrium of anionic $\mathrm{PBI}^{-}$can be represented by the following anion-exchange reaction:

$$
\mathrm{PBI}^{-}{ }_{\mathrm{aq}}+\mathrm{Tf}_{2} \mathrm{~N}^{-}{ }_{\mathrm{IL}} \rightleftharpoons \mathrm{PBI}^{-}{ }_{\mathrm{IL}}+\mathrm{Tf}_{2} \mathrm{~N}^{-}{ }_{\mathrm{aq}} .
$$

The equilibrium constant can be defined as

$$
K_{\mathrm{D}, \mathrm{PBI}}=\frac{\left[\mathrm{PBI}^{-}\right]_{\mathrm{IL}}\left[\mathrm{Tf}_{2} \mathrm{~N}^{-}\right]_{\mathrm{aq}}}{\left[\mathrm{PBI}^{-}\right]_{\mathrm{aq}}\left[\mathrm{Tf}_{2} \mathrm{~N}^{-}\right]_{\mathrm{LL}}} .
$$

Given that the variation of $\left[\mathrm{Tf}_{2} \mathrm{~N}^{-}\right]_{\mathrm{aq}}$ by the anion-exchange reaction is negligibly small compared with the solubility of $\left[\mathrm{C}_{1} \mathrm{C}_{4} \mathrm{im}\right]\left[\mathrm{Tf}_{2} \mathrm{~N}\right]$ in water $(17.0 \mathrm{mM}),{ }^{35}$ and $\left[\mathrm{Tf}_{2} \mathrm{~N}^{-}\right]_{\mathrm{aq}}$ and $\left[\mathrm{Tf}_{2} \mathrm{~N}^{-}\right]_{\mathrm{IL}}$ are constant under the stated conditions, the following equation for the apparent distribution constant of $\mathrm{PBI}^{-}\left(K_{\mathrm{D}, \mathrm{PBI}}^{\prime}\right)$ can be derived:

$$
K_{\mathrm{D}, \mathrm{PBI}}^{\prime}=\frac{\left[\mathrm{PBI}^{-}\right]_{\mathrm{IL}}}{\left[\mathrm{PBI}^{-}\right]_{\mathrm{aq}}} .
$$

The distribution ratio, $D_{\mathrm{HPBI}}$, as shown in Eq. (1), can be rewritten using the distribution constant, $K_{\mathrm{D}, \mathrm{HPBI}}$, the apparent distribution constant, $K_{\mathrm{D}, \mathrm{PBI}}^{\prime}$, and the acid dissociation constant $\left(K_{\mathrm{a}}\right)$ of HPBI as follows:

$$
D_{\mathrm{HPBI}}=\frac{K_{\mathrm{D}, \mathrm{HPBI}}+K_{\mathrm{D}, \mathrm{PBI}}^{\prime}\left(K_{\mathrm{a}} /\left[\mathrm{H}^{+}\right]_{\mathrm{aq}}\right)}{1+\left(K_{\mathrm{a}} /\left[\mathrm{H}^{+}\right]_{\mathrm{aq}}\right)} .
$$

The values of $K_{\mathrm{D}, \mathrm{HPBI}}, K_{\mathrm{D}, \mathrm{PBI}}^{\prime}$, and $K_{\mathrm{a}}$ were determined by a nonlinear least-squares fitting of the plots in Fig. 2 based on Eq. (9). The obtained values for the distribution constants in the $\left[\mathrm{C}_{1} \mathrm{C}_{4} \mathrm{im}\right]\left[\mathrm{Tf}_{2} \mathrm{~N}\right]$ system were $\log K_{\mathrm{D}, \mathrm{HPBI}}=2.88 \pm 0.01$ and $\log$ $K_{\mathrm{D}, \mathrm{PBI}}^{\prime}=0.88 \pm 0.01$. The $K_{\mathrm{D}, \mathrm{HPBI}}$ value in the $\left[\mathrm{C}_{1} \mathrm{C}_{4} \mathrm{im}\right]\left[\mathrm{Tf}_{2} \mathrm{~N}\right]$ system is higher than $K_{\mathrm{D}, \mathrm{HTTA}}\left(\log K_{\mathrm{D} \text {, HTTA }}=1.61 \pm 0.05\right.$; HTTA denotes 2-thenoyltrifluoroacetone), ${ }^{34}$ whereas the $K_{\mathrm{D}, \mathrm{PBI}}^{\prime}$ value is comparable to $K_{\mathrm{D}, \mathrm{TTA}}^{\prime}\left(\log K_{\mathrm{D}, \mathrm{TTA}}^{\prime}=0.96 \pm 0.10\right) .^{34} \quad$ In addition, the $\mathrm{p} K_{\mathrm{a}}$ value obtained by the fitting was $0.65 \pm 0.01$,

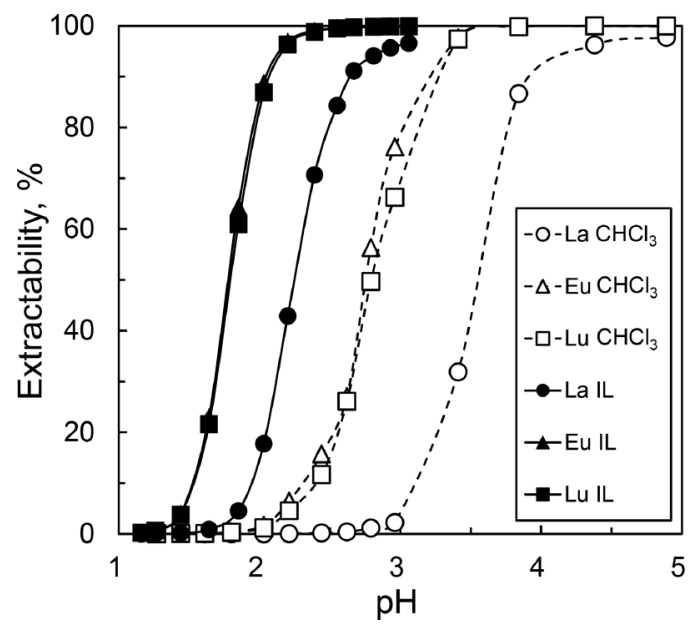

Fig. 3 Dependence of the $\operatorname{Ln}(\mathrm{III})$ ion extractability on the equilibrium $\mathrm{pH}$ value of the aqueous phase using $1 \mathrm{mM}$ HPBI in $\left[\mathrm{C}_{1} \mathrm{C}_{4} \mathrm{im}\right]\left[\mathrm{Tf}_{2} \mathrm{~N}\right]$ or $\mathrm{CHCl}_{3}$.

which is in good agreement with the reported value $\left(\mathrm{p} K_{\mathrm{a}}=\right.$ 0.68). ${ }^{36}$ This result indicates that HPBI is a powerful acidic chelating ligand compared with HTTA $\left(\mathrm{p} K_{\mathrm{a}}=6.33\right) .{ }^{37}$ It should be noted that the HPBI concentration in the IL phase after the equilibration with the aqueous phase decreases with increasing $\mathrm{pH}$ due to the strong acid dissociation of HPBI in the aqueous phase. The HPBI concentration in the IL phase at equilibrium ([HPBI $]_{\mathrm{IL}}$ ) can be calculated using the obtained $K_{\mathrm{D}, \mathrm{HPBI}}, K_{\mathrm{D}, \mathrm{PBI}}^{\prime}$, and $K_{\mathrm{a}}$ values as follows:

$$
[\mathrm{HPBI}]_{\mathrm{IL}}=\frac{[\mathrm{HPBI}]_{\mathrm{IL}, \mathrm{ini}} K_{\mathrm{D}, \mathrm{HPBI}}}{K_{\mathrm{D}, \mathrm{HPBI}}+K_{\mathrm{D}, \mathrm{PBI}}^{\prime}\left(K_{\mathrm{a}} /\left[\mathrm{H}^{+}\right]_{\mathrm{aq}}\right)+\left(1+K_{\mathrm{a}} /\left[\mathrm{H}^{+}\right]_{\mathrm{aq}}\right)},
$$

where $[\mathrm{HPBI}]_{\mathrm{IL} \text {,ini }}$ is the initial concentration of HPBI in the IL phase. The calculation of the HPBI concentration in the IL phase was applied in the slope analysis discussed later.

\section{Extraction behavior of lanthanoids in ionic and molecular diluents}

The extraction performance of the chelating agent HPBI in ionic and molecular diluents was assessed towards $\mathrm{La}^{3+}, \mathrm{Eu}^{3+}$, and $\mathrm{Lu}^{3+}$ ions as representatives of light, middle, and heavy $4 \mathrm{f}$-series, ceteris paribus. The degree of Lns extraction was compared with the two studied diluents IL vs. $\mathrm{CHCl}_{3}$ by applying the same protocol. The extractability of Lns by HPBI in $\left[\mathrm{C}_{1} \mathrm{C}_{4} \mathrm{im}\right]\left[\mathrm{Tf}_{2} \mathrm{~N}\right]$ as a function of the $\mathrm{pH}$ value of the aqueous phase, compared with that in chloroform system, can be seen in Fig. 3. The extraction $\%$ of metal ions increases with increasing $\mathrm{pH}$ in the aqueous phase in the $\mathrm{pH}$ range of $1.4-3.1$ as well as $2.2-5.0$, considering the ionic and molecular systems, respectively. As a result, the extraction efficiency of $\operatorname{Ln}(\mathrm{III})$ ions reached approximately $100 \%$ at $\mathrm{pH} 3$ in the $\mathrm{IL}$ and $\mathrm{pH} 4$ in molecular medium. At a lower $\mathrm{pH}(<1)$ the extraction in $\mathrm{IL}$ is nil, whereas at a slightly higher $\mathrm{pH}(>2)$ more than $90 \%$ of the extraction could be achieved. Furthermore, it is worth noting that HPBI exhibited a very similar selectivity facing the target metals in the two systems transferring Ln ions in the same order: $\mathrm{Lu}^{3+} \approx \mathrm{Eu}^{3+}>\mathrm{La}^{3+}$. This order was expected following the atomic number of the metals due to their decreasing ionic radii from $\mathrm{La}^{3+}$ to $\mathrm{Lu}^{3+}$. With increasing atomic number, the ionic radii decrease at constant charge (3+), and consequently the charge densities increase, and the formation of an extractable 

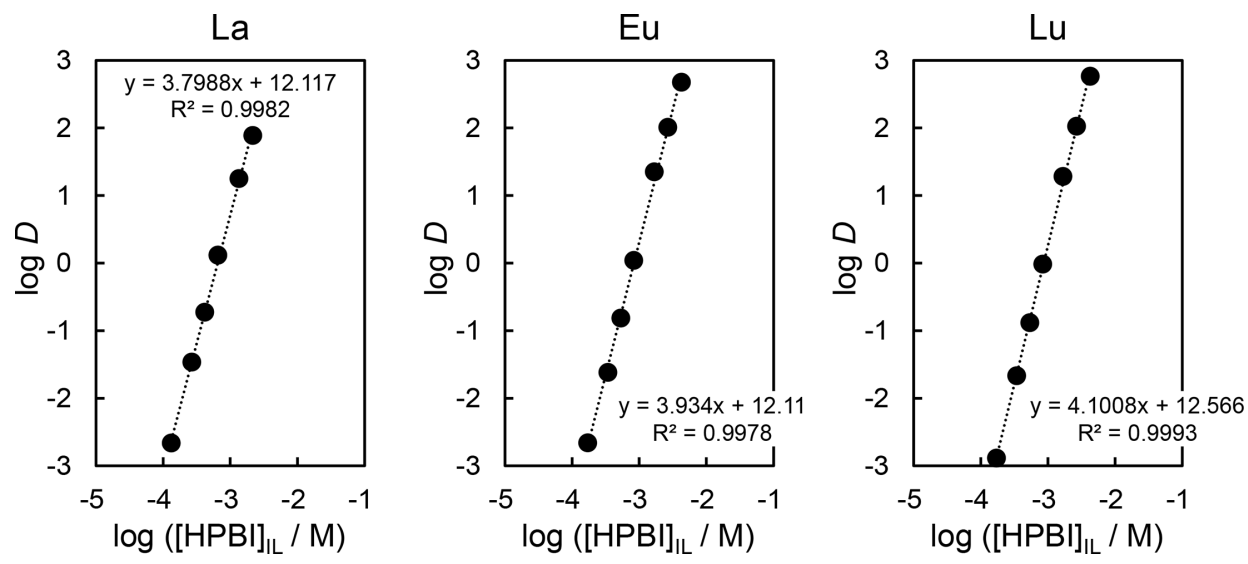

Fig. $4 \log D v s . \log [\mathrm{HPBI}]_{\mathrm{IL}}$ plots at $\mathrm{pH} 2.3$ for $\mathrm{La}^{3+}$ and $\mathrm{pH} 1.8$ for $\mathrm{Eu}^{3+}$ and $\mathrm{Lu}^{3+}$ in $\left[\mathrm{C}_{1} \mathrm{C}_{4} \mathrm{im}\right]\left[\mathrm{Tf}_{2} \mathrm{~N}\right]$. The experiment was separately performed under the presence of a single metal ion in each aqueous phase.

complex is favored. Thus, an increase of the extraction efficiency is observed going from $\mathrm{La}^{3+}$ to $\mathrm{Lu}^{3+}$. As a whole, the two systems are very efficient for Lns removing at low acidity with a HPBI compound. Additionally, the present experiments show that a complete quantitative back-extraction of Lns can be obtained easily using $1 \mathrm{M} \mathrm{HNO}_{3}$ as a stripping agent with excellent recovery independently from the extracting phase nature. Another advantage is that the process is carried out at rather lower $\mathrm{pH}$ values of the aqueous phase in a very short region $\left(\sim 1 \mathrm{pH}\right.$ unit). The half-extraction $\mathrm{pH}$ values $\left(\mathrm{pH}_{50}\right)$ at which the extractability is $50 \%$ were 2.3 for $\mathrm{La}^{3+}, 1.8$ for $\mathrm{Eu}^{3+}$, and 1.8 for $\mathrm{Lu}^{3+}$ in the IL system and 3.6 for $\mathrm{La}^{3+}, 2.8$ for $\mathrm{Eu}^{3+}$, and 2.8 for $\mathrm{Lu}^{3+}$ in the chloroform system, respectively. A notable difference between the $\mathrm{pH}_{50}$ values in the IL and chloroform systems $\left(\Delta \mathrm{pH}_{50}\right.$ approximately $1.0-1.3 \mathrm{pH}$ unit) demonstrates that the IL system can remarkably enhance the extraction performance of HPBI for Ln ions compared with the chloroform system. Furthermore, it is interesting to note that HPBI enables a quantitative partitioning of Lns from higher acidic solutions than typical $\beta$-diketones such as HTTA. ${ }^{7,9,15}$

Mechanism of lanthanoids extraction using 4-benzoyl-3-phenyl5-isoxazolone in ionic and molecular media

While metal ions generally exist at the form of neutral hydrophobic complexes in molecular liquids, charged metallic complexes highly soluble in the IL phase may pertain in this ionic solvation environment. Three fundamental classes of mononuclear Ln complexes with $\beta$-diketone (HL) in the IL solutions can be considered: ${ }^{38}$ i) neutral tris complexes $\left(\mathrm{LnL}_{3}\right)$ involving three $\beta$-diketone molecules for a $\mathrm{Ln}$ ion; ii) neutral self-adduct complexes $\left(\mathrm{LnL}_{3} \cdot \mathrm{HL}\right)$ including one protonated acidic molecule; iii) anionic tetrakis complexes $\left(\mathrm{LnL}_{4}^{-}\right)$ consisting of four $\beta$-diketone molecules and a $\mathrm{Ln}$ ion. Atanassova et al. have already demonstrated that the extraction of Ln ions using the strongly coordinating compound HPBI in a set of molecular diluents proceeds through a proton-exchange reaction, forming neutral tris complexes. ${ }^{23-27}$ The extraction mechanism and the extraction constant of the neutral tris complexes $\left(K_{\mathrm{ex}, 3}\right)$ were represented by the following equations:

$$
\begin{aligned}
& \mathrm{Ln}^{3+}{ }_{\mathrm{aq}}+3 \mathrm{HPBI}_{\mathrm{org}} \rightleftharpoons \mathrm{Ln}(\mathrm{PBI})_{3, \mathrm{org}}+3 \mathrm{H}^{+}{ }_{\mathrm{aq}}, \\
& K_{\mathrm{ex}, 3}=\frac{\left[\mathrm{Ln}(\mathrm{PBI})_{3}\right]_{\mathrm{org}}\left[\mathrm{H}^{+}\right]_{\mathrm{aq}}{ }^{3}}{\left[\mathrm{Ln}^{3+}\right]_{\mathrm{aq}}[\mathrm{HPBI}]_{\mathrm{org}}{ }^{3}},
\end{aligned}
$$

where the subscript org denotes organic phase. In this study, we confirmed that the extraction of $\operatorname{Ln}(\mathrm{III})$ ions with HPBI in the chloroform system is consistent with the previous data and can be described by Eq. (11) from slope analysis (data not shown in the figures). ${ }^{23-27}$ In addition, the values of $\log K_{\mathrm{ex}, 3}$ for $\mathrm{La}^{3+}$, $\mathrm{Eu}^{3+}$, and $\mathrm{Lu}^{3+}$ in the chloroform system were determined to be $-1.34 \pm 0.10,0.85 \pm 0.11$, and $0.73 \pm 0.10$ by a linear leastsquares fitting of the plots, respectively. Electroneutrality is an essential principle, as only neutral complexes may enter the hydrophobic molecular layer. The coordination sphere of the trivalent ion is unsaturated in this six-coordinate chelate complex, so the $\mathrm{Ln}$ (III) ion can expand its coordination sphere by adduct formation, depending on the protocol, with water molecules for example $\mathrm{LnL}_{3} \cdot\left(\mathrm{H}_{2} \mathrm{O}\right)_{\mathrm{x}}, x=2$ or 3 .

In the IL system, slope analysis of Ln extraction with HPBI was investigated as a function of the HPBI concentration in the IL phase at equilibrium (Fig. 4) in order to determine the stoichiometry of the $\mathrm{Ln}^{3+}$-HPBI complexes in the $\left[\mathrm{C}_{1} \mathrm{C}_{4} \mathrm{im}\right]\left[\mathrm{Tf}_{2} \mathrm{~N}\right]$ phase. The plots for the HPBI concentration were linear with a slope of 4 for $\mathrm{La}^{3+}, \mathrm{Eu}^{3+}$, and $\mathrm{Lu}^{3+}$ extraction, suggesting that four HPBI molecules were required to extract one $\operatorname{Ln}(\mathrm{III})$ ion into the IL, in that a 1:4 metal/ligand ratio complex was formed. The results clarify the difference in the extracted species between IL and organic solvent systems. The fourth ligand probably displaces the water molecules from the inner coordination sphere of the $\mathrm{Ln}(\mathrm{III})$ ion. ${ }^{39}$ Two candidate forms, which are neutral self-adduct complexes $\left(\mathrm{LnL}_{3} \cdot \mathrm{HL}\right)$ and anionic tetrakis complexes $\left(\mathrm{LnL}_{4}^{-}\right)$, can emarge as 1:4 complexes. To elucidate the convincing extraction mechanism, the slope analysis of Ln extraction with HPBI was investigated as a function of $\mathrm{pH}$ in the aqueous phase (Fig. 5). Here, $\log D-$ $4 \log [\mathrm{HPBI}]_{\mathrm{IL}}$ vs. $\mathrm{pH}$ plots were collected because the concentration of HPBI in the IL phase at equilibrium varies depending on the $\mathrm{pH}$ condition due to its high acidity $\left(\mathrm{p} K_{\mathrm{a}}=\right.$ $0.65 \pm 0.01)$. The value of $[\mathrm{HPBI}]_{\mathrm{IL}}$ was calculated according to Eq. (10). As shown in Fig. 5, the slopes obtained for the $\mathrm{pH}$ dependency were around 4 for $\mathrm{La}^{3+}, \mathrm{Eu}^{3+}$, and $\mathrm{Lu}^{3+}$. These results indicate that four protons from the HPBI molecules were released to extract all $\mathrm{Ln}(\mathrm{III})$ ions. Pioneering investigations of $\mathrm{Ln}^{3+}$ extraction conducted by Jensen et al. ${ }^{6,9}$ in $\left[\mathrm{C}_{1} \mathrm{C}_{4} \mathrm{im}\right]\left[\mathrm{Tf}_{2} \mathrm{~N}\right]$ medium by HTTA notified the existence of anionic tetrakis complexes $\operatorname{Ln}(\mathrm{TTA})_{4}{ }^{-}$at high ligand concentration, while at low concentration of HTTA neutral complexes $\operatorname{Ln}(\mathrm{TTA})_{3}$ were extracted. In this study, the slope analysis of $\mathrm{Ln}^{3+}$ extraction 

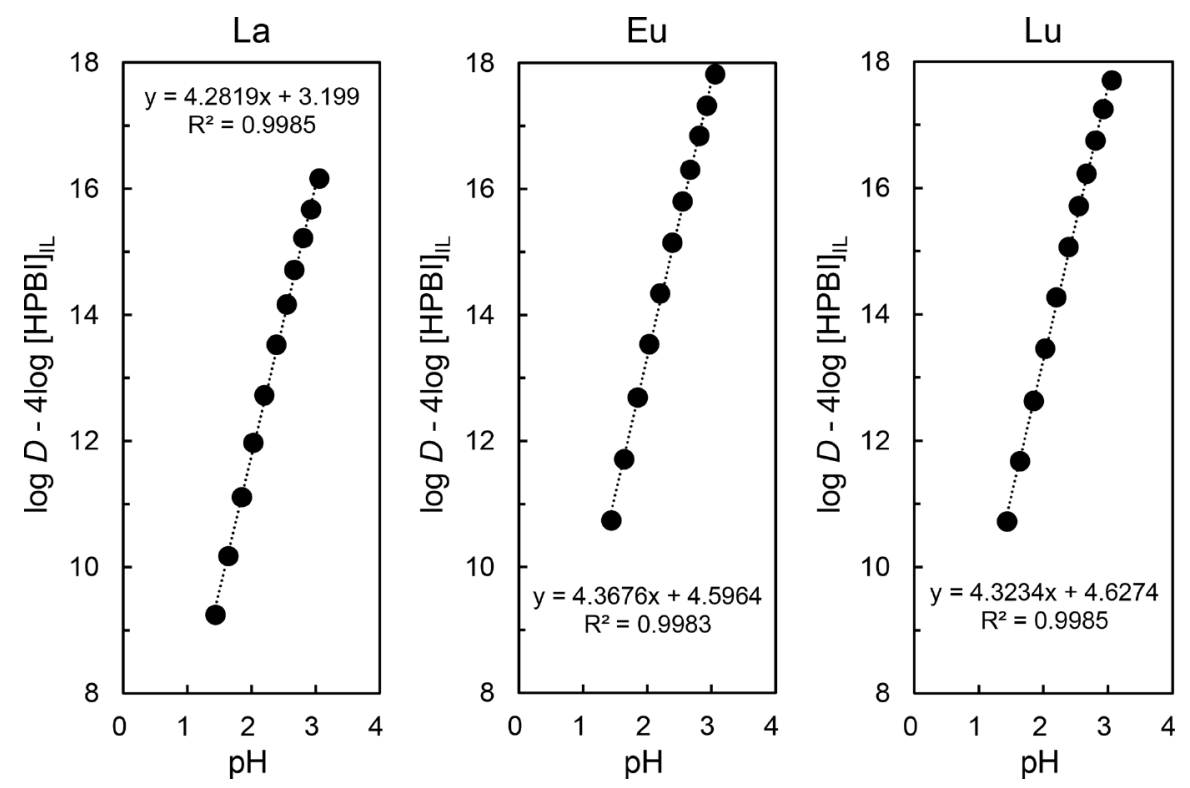

Fig. $5 \log D-4 \log [\mathrm{HPBI}]_{\mathrm{IL}} v s$. pH plots for $\mathrm{Ln}^{3+}$ extraction using $1 \mathrm{mM}$ HPBI in $\left[\mathrm{C}_{1} \mathrm{C}_{4} \operatorname{im}\right]\left[\mathrm{Tf}_{2} \mathrm{~N}\right]$.

with HPBI demonstrates that anionic tetrakis complexes $\left(\mathrm{Ln}(\mathrm{PBI})_{4^{-}}\right)$were preferentially formed even at low HPBI concentration $(1 \mathrm{mM})$ in the IL system, in contrast to the HTTA-IL systems, where a mixture of anionic terakis and neutral tris complexes was formed under the same condition. ${ }^{17,18}$ The extraction of anionic complexes is possible due to the exchange of $\left[\mathrm{Tf}_{2} \mathrm{~N}^{-}\right]$anions into the aqueous phase. The extraction of $\mathrm{Ln}^{3+}$ with HPBI in the IL system and the extraction constant of the anionic tetrakis complexes $\left(K_{\mathrm{ex}, 4}\right)$ can be expressed by the following equations:

$$
\begin{aligned}
& \mathrm{Ln}^{3+}{ }_{\mathrm{aq}}+4 \mathrm{HPBI}_{\mathrm{IL}}+\mathrm{Tf}_{2} \mathrm{~N}^{-}{ }_{\mathrm{IL}} \rightleftharpoons \mathrm{Ln}(\mathrm{PBI})_{4^{-}}{ }_{\mathrm{IL}}+ \\
& 4 \mathrm{H}^{+}{ }_{\mathrm{aq}}+\mathrm{Tf}_{2} \mathrm{~N}^{-}{ }_{\mathrm{aq}},
\end{aligned}
$$

Given that $\left[\mathrm{Tf}_{2} \mathrm{~N}^{-}\right]_{\mathrm{aq}}$ and $\left[\mathrm{Tf}_{2} \mathrm{~N}^{-}\right]_{\mathrm{IL}}$ are constant under the stated conditions as described above, Eq. (14) can be rewritten as follows:

$$
K_{\mathrm{ex}, 4}^{\prime}=\frac{\left[\mathrm{Ln}(\mathrm{PBI})_{4}{ }^{-}\right]_{\mathrm{IL}}\left[\mathrm{H}^{+}\right]_{\mathrm{aq}}{ }^{4}}{\left[\mathrm{Ln}^{3+}\right]_{\mathrm{aq}}[\mathrm{HPBI}]_{\mathrm{LL}}{ }^{4}} .
$$

The values of $\log K_{\text {ex,4 }}^{\prime}$ for $\mathrm{La}^{3+}, \mathrm{Eu}^{3+}$, and $\mathrm{Lu}^{3+}$ in the $\left[\mathrm{C}_{1} \mathrm{C}_{4} \mathrm{im}\right]\left[\mathrm{Tf}_{2} \mathrm{~N}\right]$ system were determined to be $3.60 \pm 0.02$, $5.12 \pm 0.03$, and $5.07 \pm 0.03$, respectively. As noted, the ionic character of ILs has important implications in coordination solution chemistry in the process of solvating charged metal complex (like $\left.\left[\mathrm{C}_{1} \mathrm{C}_{4} \mathrm{im}\right]\left[\mathrm{Ln}(\mathrm{PBI})_{4}\right]\right)$ as well as by the release of anionic components to the aqueous phase associating with ionexchange mechanism in a rather satisfactory way. According to the reaction for each extracted $\mathrm{Ln}^{3+}$ ion into the $\mathrm{IL}$, one anion $\left[\mathrm{Tf}_{2} \mathrm{~N}^{-}\right]$is lost by being transferred to the aqueous phase. Under this circumstances, not only the coordination power of ligand, but also the ion-exchange ability of IL would likely be important factors determining the extraction mechanism.

\section{Conclusions}

In the present study, the distribution bahavior of HPBI between the IL and aqueous phases was investigated, and the distribution constants and the acid dissociation constant of HPBI were determined. The extraction behavior of lanthanoids with HPBI was compared between the IL and organic solvent systems. HPBI in IL provided a remarkably high extraction performance for lanthanoids compared with that in chloroform. The existance of anionic lanthanoid complexes $\left(\mathrm{Ln}(\mathrm{PBI})_{4}{ }^{-}\right)$coordinated by $\mathrm{PBI}^{-}$in ionic medium during solvent extraction process has been established hitherto. On the other hand, in the chloroform system, the neutral tris chelates $\left(\mathrm{Ln}(\mathrm{PBI})_{3}\right)$ were usually formed with this ligand. We hope that the present findings will be contributory to the further development of separation chemistry for various metal ions.

\section{Acknowledgements}

The authors are grateful to the Matsumae International Foundation for the research fellowship grant 17G03. This work was financially supported by JSPS KAKENHI Grant Number $16 \mathrm{~K} 00619$.

\section{References}

1. "Application of Ionic Liquids on Rare Earth Green Separation and Utilization", ed. J. Chen, 2016, Springer.

2. F. Kubota, Y. Baba, and M. Goto, Solvent Extr. Res. Dev., Jpn., 2012, 19, 17.

3. P. Mohapatra, Dalton Trans., 2017, 46, 1730.

4. Y. Liu, J. Chen, and D. Li, Sep. Sci. Technol., 2012, 47, 223.

5. M. Atanassova, ACS Sustainable Chem. Eng., 2016, 4, 2366.

6. M. Jensen, M. Borkowski, I. Laszak, J. Beitz, P. Rickert, and M. Dietz, Sep. Sci. Technol., 2012, 47, 233. 
7. N. Hirayama, H. Okamura, K. Kidani, and H. Imura, Anal. Sci., 2008, 24, 697.

8. C. Janssen, N. Macias-Ruvalcaba, M. Aguilar-Martinez, and M. Kobrak, Int. Rev. Phys. Chem., 2015, 34, 591.

9. M. Jensen, J. Neuefeind, J. Beitz, S. Skanthamukar, and L. Soderholm, J. Am. Chem. Soc., 2003, 125, 15466.

10. K. Shimojo, H. Okamura, N. Hirayama, S. Umetani, H. Imura, and H. Naganawa, Dalton Trans., 2009, 4850.

11. H. Okamura, A. Ikeda-Ohno, T. Saito, N. Aoyagi, H. Naganawa, N. Hirayama, S. Umetani, H. Imura, and K. Shimojo, Anal. Chem., 2012, 84, 9332.

12. K. Shimojo, K. Kurahashi, and H. Naganawa, Dalton Trans., 2008, 5083.

13. M. Atanassova and V. Kurteva, Sep. Purif. Technol., 2017, $183,226$.

14. K. Nakashima, F. Kubota, T. Maruyama, and M. Goto, Anal. Sci., 2003, 19, 1097.

15. H. Okamura, N. Hirayama, K. Morita, K. Shimojo, H. Naganawa, and H. Imura, Anal. Sci., 2010, 26, 607.

16. M. Atanassova, V. Kurteva, L. Lubenov, and I. Billard, Sep. Sci. Technol., 2016, 51, 290.

17. H. Okamura, H. Sakae, K. Kidani, N. Hirayama, N. Aoyagi, T. Saito, K. Shimojo, H. Naganawa, and H. Imura, Polyhedron, 2012, 31, 748.

18. H. Okamura, N. Aoyagi, K. Shimojo, H. Naganawa, and H. Imura, $R S C A d v$., 2017, 7, 7610.

19. K. Shimojo and M. Goto, Anal. Chem., 2004, 76, 5039.

20. K. Shimojo and M. Goto, Chem. Lett., 2004, 33, 320.

21. M. Atanassova, V. Kurteva, L. Lubenov, and I. Billard, RSC Adv., 2014, 4, 38820.

22. M. Atanassova, V. Kurteva, L. Lubenov, S. Varbanov, and I. Billard, New J. Chem., 2015, 39, 7932.

23. M. Petrova and V. Kurteva, J. Chem. Eng. Data, 2014, 59,
1295.

24. M. Atanassova, V. Lachkova, N. Vassilev, S. Varbanov, and I. Dukov, Polyhedron, 2010, 29, 655.

25. M. Petrova, V. Lachkova, N. Vassilev, and S. Varbanov, Ind. Eng. Chem. Res., 2010, 49, 6189.

26. M. Atanassova and I. Dukov, Sep. Purif. Technol., 2010, 74 , 300.

27. M. Atanassova, Solvent Extr. Ion Exch., 2009, 27, 159.

28. A. Jyothi and G. Rao, Bull. Chem. Soc. Jpn., 1988, 61, 4497.

29. P. Pavithran and M. L. P. Reddy, Radiochim. Acta, 2004 92, 31.

30. P. Pavithran and M. L. P. Reddy, Radiochim. Acta, 2003 , 91, 163.

31. P. Mohapatra and V. Manchanda, Radiochim. Acta, 2003 , 91, 705.

32. S. Banerjee, P. Mohapatra, A. Bhattacharya, S. Basu, and V. Manchanda, Radiochim. Acta, 2004, 92, 95.

33. K. Shimojo, N. Kamiya, F. Tani, H. Naganawa, Y. Naruta, and M. Goto, Anal. Chem., 2006, 78, 7735 .

34. K. Kidani and H. Imura, Talanta, 2010, 83, 299.

35. M. G. Freire, P. J. Carvalho, R. L. Gardas, I. M. Marrucho, L. M. N. B. F. Santos, and J. A. P. Coutinho, J. Phys. Chem. $B, 2008,112,1604$.

36. M. Bouby, I. Billard, G. Duplâtre, J.-P. Simonin, O. Bernard, J.-P. Brunette, and G. Goetz-Grandmont, Phys. Chem. Chem. Phys., 1999, 1, 3765.

37. T. Sekine, Y. Hasegawa, and N. Ihara, J. Inorg. Nucl. Chem., 1973, 35, 3968.

38. M. Atanassova, V. Kurteva, and I. Billard, Anal. Sci., 2015 , $31,917$.

39. V. Jordanov, M. Atanassova, and I. Dukov, Sep. Sci Technol., 2002, 37, 3349. 